\title{
Women and stroke patients are more at risk for fall- related injury among older persons
}

\author{
Sulistyowati Tuminah*, Woro Riyadina*, and Aprildah Nur Sapardin**
}

\begin{abstract}
*Research and Development Center of Community Health Efforts

**Health Resource and Services

Center, Health Research and Development Agency, Ministry of Health, Repubic of Indonesia

Correspondence address

Sulistyowati Tuminah

Jl. Percetakan Negara 29,

Jakarta Pusat

Email: sdarjoko@yahoo.com /

watidarjoko@gmail.com

Univ Med 2016;35:10-8

DOI: 10.18051/UnivMed.2016.v35.10-18 pISSN: 1907-3062 / eISSN: 2407-2230

This open access article is distributed under

\section{BACKGROUND}

In Indonesia, the prevalence of injury has increased from $7.9 \%$ in 2007 to $8.2 \%$ in 2013 . Among older persons, falls were the main cause of injury. The objective of this study was to determine the major risk factors and the magnitude of the risk for fall-related injury in older persons.

\section{METHODS}

A study of cross-sectional design was conducted on 4,222 respondents aged 60 years and over. Injury was defined as fall-related injury occurring in the previous 12 months that disturbed activity daily living (ADL). Data collection was done by: 1) interview about sociodemographics and health (including hearing impairment, non-communicable diseases and injury) using a questionnaire, 2) measurement of blood pressure and anthropometry (body mass index), 3) examination of vision in the right and left eyes using tumbling E cards and pinhole eye covers. Data were analyzed using the chi square test and multiple logistic regression with 0.05 significance level.
\end{abstract} a Creative Commons Attribution-Non Commercial-Share Alike 4.0 International License

\section{RESULTS}

After controlling for age, occupation, vision disorder, educational level and economic status, older women had a 2.0-fold increased risk for fallrelated injury compared to men ( ${ }^{\mathrm{a}} \mathrm{OR}=2.3 ; 95 \% \mathrm{CI}$ : $1.93-2.73$; $\left.\mathrm{p}=0.000\right)$; subjects with a history of stroke had a 2.1 -fold increased risk for fallrelated injury compared to those without a history of stroke $\left({ }^{\mathrm{a}} \mathrm{OR}=2.07\right.$; 95\% CI: 1.38-3.09; $\mathrm{p}=0.000$ ). Educational level was a confounding factor.

\section{CONCLUSION}

Women and stroke sufferers were at higher risk of fall-related injury among older persons. Prevention of fall-related injury should be done by older persons through periodic control of their health condition.

Keywords: Injury, stroke, fall, older persons 


\section{INTRODUCTION}

The prevalence falls dan fall-related injuryin populasi lanjut usia (lansia) semakin meningkat. Falls are one of the causes of death from injury among older persons. Around 20$30 \%$ of older persons with moderate and severe injury may suffer from loss of independence, decrease in quality of life and eventually death. ${ }^{(1)}$ In Indonesia, the prevalence of injury showed a slightly increasing trend from 7.9 percent in Riskesdas 2007 to 8.2 percent in Riskesdas 2013. ${ }^{(2,3)}$ Of the percentage of injured respondents, the proportion of falls $(40.9 \%)$ was the second greatest cause of injury after land transport accidents $(47.7 \%){ }^{(3)}$

The risk factors of falls are categorized as internal and external. Internal factors comprise age, gender, problems of balance associated with walking style, functional and cognitive impairment, visual problems, and comorbidities such as depression, stroke, parkinsonism, and arthritis. External factors are closely associated with home hazards, such as slipping, stumbling, and falling from loss of balance, e.g. wet floors, slippery floors, uneven floor surfaces, inadequate lighting, absence of handholds, absence of walking aids, and others. ${ }^{(4-7)}$ The study results of Rodriguez et al. ${ }^{(8)}$ showed that falls were more frequently experienced by female older persons and older persons aged 80 years and above. According to Jalayondeja ${ }^{(9)}$ falls are common occurrences in healthy older persons and are more frequently experienced by stroke patients. In individuals with stroke, the incidence of firsttime falls ranged from 3.8 to $22 \%$, whereas the incidence of falls was around 1.3-6.5 times in the year following a stroke event.

Data on fall-related injury in Riskesdas 2007 and 2013 were respectively representative of data from the national level down to the district level in Indonesia. However in Riskesdas 2007, data on fall-related injury comprised all types of fall-related injury, including slight injury, so that its prevalence was greater. ${ }^{(10)}$ This is in contrast with the data obtained in Riskesdas
2013, which were focussed exclusively on fallrelated injury that impaired the activities of daily living (ADL), and which constitute the novelty of the present study. The objective of the present study was to determine the most dominant risk factors of fall-related injury among older persons in Indonesia and the magnitude of the risk.

\section{METHODS}

\section{Design of the study}

This advanced analysis of a subset of the Riskesdas 2013 data was of cross sectional design. The complete advanced analysis consisting of the writing of the proposal, protocol, and a request for data to the data management laboratory (Lab mandat), data analysis, and writing of the report, was conducted from January to December 2014.

\section{Study subjects}

The respondents who were selected for the Riskesdas 2013 sample came from 33 provinces. The inclusion criteria were: 1) male and female respondents, 2) aged 60 years and above (older persons), 3) respondents who in the previous 12 months experienced fall-related injury that impaired their ADL. The number of respondents meeting the inclusion criteria was 4,222 persons.

\section{Interviews}

The interviews were conducted on elderly respondents aged 60 years and above. The age of the respondents was the difference in years between the last birthday and the birth date. These data were of ordinal scale and were divided into 3 categories, i.e. 60-69 years, 70-79 years, 80 years, and above. The dependent (outcome) variable was fall-related injury and was obtained through 2 questions: "Within the last 12 months, did the respondent experience events that resulted in injuries?" and "What were the causes of these injuries?". ${ }^{(11)}$ The injuries referred to were injuries that impaired ADL. The responses to the experiencing of injuries were divided into 2 categories, i.e. "Yes" (experienced injuries) and 
"No", while the cause of injury that was the focus of the present study was falls. In this case falls were causes of unintentional injury and resulted in the person falling to the ground, e.g. gliding, stumbling, falling from heights. ${ }^{(12)}$ The causes of injuries were grouped into 2 categories, i.e. "Due to falls" and "Not due to falls" (land transport accidents, injuries from sharp/blunt objects, burns/scalds, animal attacks/bites, etc.). The study sample consisted of the respondents who answered "Yes" (had experienced injuries) and "Falls" as the cause.

Other independent variables that were collected comprised socio-economic factors (education, occupation, and economic status), biological factors (gender, history of illness, health status, and physical condition). The education of the respondents was the final completed educational stage of the respondents who received diplomas. The education of the respondents were grouped into 3 categories, i.e. low (no schooling/never went to school, did not finish primary school and finished primary school), middle (finished junior high school and finished senior high school), and high (finished D1/D2/D3 and finished tertiary education). The occupation of the respondents was a composite of their occupational status and the type of their main occupation. The main occupation of the respondents was grouped into 5 categories, i.e. non-employed, employee, entrepreneur, farmer/ fisher/laborer and others. The economic status was determined according to the quintile of ownership index, which was calculated from several variables of ownership of durable goods. The economic status was grouped into 5 categories, i.e. lowest, lower middle, middle, upper middle, and upper.

What was meant by "History of illness of the respondents" in this case were the diseases suffered by the respondents based on the diagnosis established by health personnel (physicians/nurses/midwifes). For example, diagnosis of hypertension, or consumption of anti-hypertensive medications, coronary heart disease (CHD) or heart failure, renal disease, diseases of the joints/rheumatism or stroke. Respondents were said to have a history of hypertension if they were diagnosed as having hypertension by health personnel or had never been diagnosed as having hypertension by health personnel but consumed anti-hypertensive medications. ${ }^{(3)}$ The responses for history of illness was divided into 2 categories, i.e "Yes" and "No".

What was meant by "Health status of respondents" in this analysis was the health condition of the respondents at the time of data collection, e.g. presence of high blood pressure (hypertension), visual or hearing impairment. The information on blood pressure and visual impairment was obtained by measurement or examination, whereas the information on hearing impairment was obtained from the interviews based on the report of the respondents. The response options were 1) Yes, in one ear; 2) Yes, in both ears; 3) Yes, fluctuating hearing impairment; 4) No hearing impairment; 8) Do not know. In this analysis, hearing impairment was grouped into 2 categories, i.e. "Yes" (response code 1,2, or 3) or "No" (response code 4 or 8$){ }^{(13)}$

\section{Measurements}

Blood pressure was determined using an Omron IA1 digital tensimeter on the left arm, and performed twice with a 2-3 minute interval. If the results of the two determinations differed $\geq 10 \mathrm{~mm} / \mathrm{Hg}$ for systolic or diastolic blood pressure, a third measurement was done after a rest of 2-3 minutes. High blood pressure (hypertension) was grouped according to the guidelines of the $8^{\text {th }}$ Joint National Committee (JNC) for 2014. ${ }^{(14)}$ However, in this study blood pressure was categorized into 2, i.e. high (hypertension stage 1 and 2) and normal (normotension and prehypertension). For hypertension associated with health status, the respondents were said to have hypertension if they had a history of hypertension or had hypertension at the time of examination or if the blood pressure at the time of measurement was 
not high because they had previously taken antihypertensive medications. If at the time of measurement the blood pressure of the respondents was not high but the respondents had previously consumed anti-hypertensive medications, this was called controlled hypertension. The physical condition in this case was seen from the body mass index (IMT) status that was obtained from the anthropometric measurements (weight and height). Weight was measured using Camry digital scales with a capacity of $150 \mathrm{~kg}$ and precision of $100 \mathrm{~g}$. The respondents were recommended to wear thin or the lightest clothing, and were weighed in the standing position without footwear. Height was measured in the upright position using a multifunctional height measuring instrument with a capacity of 2 meters and precision of $0.1 \mathrm{~cm}$. The body mass index was obtained by first measuring weight and height, then calculating with the formula:

$\mathrm{BMI}=$ weight $(\mathrm{kg}) /$ height $(\mathrm{m})^{2}$

In general, obesity was divided into 5 categories obtained from the BMI classification for Asians according to the International Obesity Task Force (IOTF). ${ }^{(15)}$ These obesity categories were underweight (BMI <18.5), normal (BMI 18.5-22.9), overweight (BMI 23.0-24.9), obese 1 (BMI 25.0-29.9) and obese 2 (BMI 30 or higher). In this study the BMI was grouped into 2 categories only, i.e. obese (BMI 25 or higher) and non-obese (BMI less than 25).

\section{Visual examination}

Visual impairment may be determined by visual acuity testing on both eyes. The instruments used were a 6-m measuring tape, one set of tumbling E cards (of great, medium, and small sizes), and eye-shields with a pinhole. The eye examination was started on the right eye of the respondent, without a pinhole. The response options for the visual examination results were as follows: 1) capable of seeing small E cards (at a distance of $6 \mathrm{~m}$ );2) not capable of seeing small E cards, but capable of seeing medium E cards (at a distance of $6 \mathrm{~m}$ ); 3) not capable of seeing medium E cards, but capable of seeing large E cards (at a distance of $6 \mathrm{~m}$ ); 4) not capable of seeing large $E$ cards (at a distance of $6 \mathrm{~m}$ ), but capable of seeing large $\mathrm{E}$ cards (at a distance of $3 \mathrm{~m})$; 5) not capable of seeing large E cards at a distance of $3 \mathrm{~m}$; 6) cannot be examined.

If there is slight visual impairment (code 2), low vision (code 3 and 4) or blindness (code 5), then it is recommended to perform a pinhole examination. After the columns for examination without and with pinhole of the right eye have been completely filled in, this is followed by examination of the left eye. Visual impairment was grouped into 2 categories, i.e. yes and no. Respondents were said to have visual impairment (yes) if both eyes had codes $2,3,4$, or 5 . Respondents were said not to have visual impairment if either one of the eyes had code $1 .^{(13)}$

\section{Data analysis}

The data were analyzed using: 1) bivariate analysis (chi square) to determine differences between the proportions of the dependent and independent variables; 2) multiple logistic regression analysis to determine the relationship between females and stroke patients with regard to fall-related injury in older persons, after controlling for confounding variables.

\section{Ethical clearance}

This protocol of the Basic Health Research (Riset Kesehatan Dasar, Riskesdas) for the year 2013 has been accorded ethical clearance from the Ethics Commission of the Health Research and Development Agency, Ministry of Health, Repubic of Indonesia.

\section{RESULTS}

The data on fall-related injury in older persons that could be analyzed comprised 4,222 cases $(65.4 \%)$. Based on biological factors (Table 1), the proportion of older persons with fall-related injury was increased with increasing age. There were more female elderly with fall- 
Table 1. Frequency distribution of fall-related injury in older persons by biological factors

\begin{tabular}{|c|c|c|c|c|}
\hline \multirow[b]{2}{*}{ Biological factors } & \multirow[b]{2}{*}{$\begin{array}{l}\text { Injured eld erly } \\
\text { (n) }\end{array}$} & \multicolumn{2}{|c|}{ Injured elderly } & \multirow[b]{2}{*}{$\mathbf{p}$} \\
\hline & & $\frac{\text { Falls }}{\%}$ & $\frac{\text { Non-falls }}{\%}$ & \\
\hline Age (years) & & & & 0.000 \\
\hline 80 and above & 817 & 80.2 & 19.8 & \\
\hline $70-79$ & 2,101 & 72.4 & 27.6 & \\
\hline $60-69$ & 3,542 & 57.7 & 42.3 & \\
\hline Gender & & & & 0,000 \\
\hline Male & 2,790 & 51.6 & 48.4 & \\
\hline Female & 3,671 & 75.8 & 24.2 & \\
\hline Obese & & & & 0.487 \\
\hline Yes & 1,131 & 62.6 & 37.4 & \\
\hline No & 4,766 & 64.3 & 35.7 & \\
\hline Hypertension (dagnosed) / m edications & & & & 0.000 \\
\hline Yes & 2,172 & 70.7 & 29.3 & \\
\hline No & 4,288 & 62.6 & 37.4 & \\
\hline Coronary heart disease & & & & 0.371 \\
\hline Yes & 130 & 71.1 & 28.9 & \\
\hline No & 6,330 & 65.2 & 34.8 & \\
\hline Heart failure & & & & 0.016 \\
\hline Yes & 26 & 85.3 & 14.7 & \\
\hline No & 6,434 & 65.3 & 34.7 & \\
\hline Renal disease & & & & 0.191 \\
\hline Yes & 70 & 76.8 & 23.2 & \\
\hline No & 6,391 & 65.2 & 34.8 & \\
\hline Joint diseaseffheumatism & & & & 0.019 \\
\hline $\begin{array}{l}\text { Yes } \\
\text { No }\end{array}$ & $\begin{array}{l}2,414 \\
4,047\end{array}$ & $\begin{array}{l}68.1 \\
63.7\end{array}$ & $\begin{array}{l}31.9 \\
36.3\end{array}$ & \\
\hline Str oke & & & & 0.000 \\
\hline Yes & 341 & 79.8 & 20.2 & \\
\hline No & 6,119 & 64.5 & 35.5 & \\
\hline Hypertension & & & & 0.005 \\
\hline Yes & 4,162 & 67.2 & 32.8 & \\
\hline No & 2,298 & 62.0 & 38.0 & \\
\hline V isual impairm ent & & & & 0.000 \\
\hline Present & 4,579 & 69.5 & 30.5 & \\
\hline Absent & 1,881 & 55.2 & 44.8 & \\
\hline Hearing i mp airm ent & & & & 0.000 \\
\hline Present & 1,706 & 72.3 & 27.7 & \\
\hline Absent & 4,754 & 62.9 & 37.1 & \\
\hline
\end{tabular}

related injury (75.8\%) than male elderly. With regard to physical condition, there were no significant differences between the proportion of obese older persons with fall-related injury and that of the non-obese.

On the other hand, with regard to history of illness, the proportion of older persons with fall-related injury was larger in respondents who had been diagnosed by health personnel as having hypertension/consumed anti-hypertensive medications, heart failure, renal disease, diseases of the joints/rheumatism or stroke. Similarly with respondents who had coronary heart disease, although the differences in proportion were not significant. While according to the health status of the respondents at the time of data collection, there were more older persons with fall-related injury among the respondents with hypertension, and with visual or hearing impairment.

From the results of the bivariate analysis, the variables that could be included in the multivariate analysis were age, gender, history 
of illness (hypertension/medications, heart failure, renal disease, diseases of the joints/ rheumatism and stroke, health status (hypertension, visual impairment and hearing impairment), education, occupation and economic status. The highest proportion of older persons with fall-related injury was found among the respondents with low educational level, unemployed, with lowest econmoic status (Table 2).

The results of multivariate analysis showed that the risk of older persons for being injured by falls increased with increasing age, with the magnitude of the risk ( ${ }^{\mathrm{a}} \mathrm{OR}=1.94 ; 95 \% \mathrm{CI}: 1.46$ $2.58 ; \mathrm{p}=0.000$ ) for the age group of 80 years and older. Female older persons had a 2.3 -fold increased risk for fall-related injury $\left({ }^{\mathrm{a}} \mathrm{OR}=2.30 ; 95 \%\right.$ CI: $\left.1.93-2.73 ; \mathrm{p}=0.000\right)$ in comparison with male older persons. Older persons with a history of stroke had a 2.1-fold increased chance of fall-related injury $\left({ }^{\mathrm{a}} \mathrm{OR}=2.07 ; 95 \%\right.$ CI: $\left.1.38-3.09 ; \mathrm{p}=0.000\right)$ in comparison with older persons without stroke. Older persons with visual impairment had a 1.4fold increased chance of suffering from fallrelated injury ( ${ }^{\mathrm{a} O R}=1.36$; $95 \% \mathrm{CI}: 1.14-1.64$; $\mathrm{p}=0.001)$ in comparison with older persons without impaired vision (Table 3).

\section{DISCUSSION}

Falls in older persons are the main cause of morbidity and mortality from unintentional injury in the United States in 2006, accounting for $45.4 \%$. $^{(16)}$ This figure is lower than the prevalence of fall-related injury in older persons (aged $\geq 60$ years) in the year 2013 in Indonesia $(65.4 \%)$. This may be caused by the relative low socio-economic conditions of the Indonesian community so that an advanced age older persons must still be more actively working to meet their necessities of life.

From the aspect of age, the risk of older persons to experience fall-related injury increases with advancing age. This agrees with the study by Pi et al. ${ }^{(17)}$ in China, who found that in the majority of cases falls occurred in individuals who were over 80 years of age. However, in the study conducted by Orces ${ }^{(18)}$ the investigators found different results. This may be because in Indonesia many older persons have low educational level and lower-middle economic status, so that in their old age they have to continue working hard. In general, persons with low educational level perform more physical work. With increasing age, the body becomes physically weaker through exhaustion. Therefore

Table 2. Associations between socio-economic factors and fall-related injury in older persons

\begin{tabular}{|c|c|c|c|c|}
\hline \multirow{3}{*}{ Socioeconom ir factors } & \multirow{3}{*}{$\stackrel{\text { n }}{\text { Injured eld erly }}$} & \multicolumn{2}{|c|}{ Injured elderly } & \multirow{3}{*}{$\mathbf{p}$} \\
\hline & & Falls & Non-falks & \\
\hline & & $\%$ & $\%$ & \\
\hline Education & & & & 0.000 \\
\hline Low & 5,536 & 67.5 & 32.5 & \\
\hline Middle & 763 & 53.0 & 47.0 & \\
\hline High & 162 & 48.6 & 51.4 & \\
\hline Occupation & & & & 0.000 \\
\hline No work & 3,493 & 74.3 & 25.7 & \\
\hline Employee & 123 & 44.5 & 55.5 & \\
\hline Entrepreneur & 509 & 51.8 & 48.2 & \\
\hline $\mathrm{F}$ armer/fisher/laborer & 2151 & 56.0 & 44.0 & \\
\hline Others & 184 & 55.6 & 44.4 & \\
\hline E conomic status & & & & 0.000 \\
\hline Lowest & 1,394 & 70.0 & 30.0 & \\
\hline Lower- mi ddle & 1,606 & 65.7 & 34.3 & \\
\hline Middle & 1,481 & 67.3 & 32.7 & \\
\hline Upper-middle & 1,220 & 62.6 & 37.4 & \\
\hline Uppex & 760 & 56.6 & 43.4 & \\
\hline
\end{tabular}


Table 3. Multiple logistic regression analysis of risk factors for fall-related injury in older persons

\begin{tabular}{|c|c|c|c|c|c|c|}
\hline \multirow{3}{*}{ Risk factors } & \multirow{3}{*}{$\begin{array}{c}\text { N } \\
\text { Injured } \\
\text { elerly }\end{array}$} & \multicolumn{2}{|c|}{ Injured elderly } & \multirow{3}{*}{$\begin{array}{c}\text { Adjusted } \\
\text { Odds } \\
\text { Ratio }\end{array}$} & \multirow{3}{*}{$\begin{array}{c}95 \% \\
\text { Confidence } \\
\text { Interval }\end{array}$} & \multirow{3}{*}{$\mathbf{p}$} \\
\hline & & Falk & Non-falls & & & \\
\hline & & $\%$ & $\%$ & & & \\
\hline Age (years) & & & & & & 0.000 \\
\hline 80 and above & 817 & 80.2 & 19.8 & 194 & $1.46-2.58$ & \\
\hline $70-79$ & 2,101 & 72.4 & 27.6 & 1.47 & $1.22-1.77$ & \\
\hline $60-69$ & 3,542 & 57.7 & 42.3 & 100 & Reference & \\
\hline Gender & & & & & & 0.000 \\
\hline Female & 3,671 & 75.8 & 24.2 & 230 & $1.93-2.73$ & \\
\hline Male & 2,790 & 51.6 & 48.4 & 100 & Reference & \\
\hline Stroke & & & & & & 0.000 \\
\hline Yes & 341 & 79.8 & 20.2 & 207 & $1.38-3.09$ & \\
\hline No & 6,119 & 64.5 & 35.5 & 100 & Reference & \\
\hline V isual impairment & & & & & & 0.001 \\
\hline Present. & 4,579 & 69.5 & 30.5 & 136 & $1.14-1.64$ & \\
\hline Absent & 1,881 & 55.2 & 44.8 & 100 & Reference & \\
\hline Education* & & & & & & 0.085 \\
\hline Low & 5,536 & 67.5 & 32.5 & 157 & $0.92-2.69$ & \\
\hline Middle & 763 & 53.0 & 47.0 & 126 & $0.72-2.20$ & \\
\hline High & 162 & 48.6 & 51.4 & 100 & Reference & \\
\hline Occupati on & & & & & & 0.001 \\
\hline No wotk & 3,493 & 74.3 & 25.7 & 159 & $1.06-2.38$ & \\
\hline Employee & 123 & 44.5 & 55.5 & 105 & $0.56-1.97$ & \\
\hline Entrepreneur & 509 & 51.8 & 48.2 & 1.12 & $0.69-1.82$ & \\
\hline Farmer/fisher/laborer & 2151 & 56.0 & 44.0 & 108 & $0.71-1.62$ & \\
\hline Lainnya & 184 & 55.6 & 44.4 & 100 & Reference & \\
\hline E commic status & & & & & & 0.036 \\
\hline Lowest & 1,394 & 70.0 & 30.0 & 158 & $1.15-2.16$ & \\
\hline Lower-middle & 1,606 & 65.7 & 34.3 & 128 & $0.95-1.71$ & \\
\hline Middle & 1,481 & 67.3 & 32.7 & 1.44 & $1.08-1.93$ & \\
\hline Upper-middle & 1,220 & 62.6 & 37.4 & 1.17 & $0.87-1.58$ & \\
\hline Upper & 760 & 56.6 & 43.4 & 100 & Reference & \\
\hline
\end{tabular}

their risk of experiencing fall-related injury also increases. According to gender, female older persons have a 2.3-fold greater risk of fall-related injury than do males. This is in agreement with the study results of Kuang et al. ${ }^{(19)}$ showing that females have a 2.3 fold greater risk of falls. This is because female older persons are at higher risk for osteoporosis than are males. The presence of osteoporosis increases the risk for fractures after falls. ${ }^{(10,20)}$ On the other hand, our results differ from the study results of Grundstrom et al. ${ }^{(16)}$ who found a higher risk of fall-related injury in males than in females.

With regard to history of illness, older persons who ever had stroke had a 2.1-fold increased risk of experiencing injury from falls. Similar results were obtained by Thurman et al. ${ }^{(21)}$ and Orces ${ }^{(18)}$ who found that subjects with stroke had a greater risk of falls in comparison with subjects without stroke. This is because in general stroke attacks decrease the functions of the patient's extremities and disturb the body balance so increasing the risk of falls. Older persons with visual impairment have a 1.4-fold higher risk of fall-related injury in comparison with older persons without impaired vision. This is in accordance with the study results of Kuang et al. ${ }^{(19)}$ who found that visual impairment increases the risk of falls almost 2-fold in comparison with normal subjects. This is because at their age (60 years and above), the older respondents usually have visual impairment and move less actively, thus decreasing their strength and balance, which increases their risk of falls.

Our study results showed that educational level was not a risk factor for falls, which differs 
from the study results of Hayashi et al. ${ }^{(22)}$ in Japan and Qader et al. ${ }^{(23)}$ in Iraq. These investigators found that the risk of injury from falls was significantly higher in older persons with low educational level in comparison with those of older persons with high educational level. In contrast, with regard to the lowest ownership index (socioeconomic status), our study showed similar results with those of the studies by Hayashi et $\mathrm{al}^{(22)}$ and Qader et al, ${ }^{(23)}$ in that the risk of falls in older persons with low socio-economic status was significantly greater than in older persons with high socio-economic status. This is because the respondents with high socio-economic status have better welfare, nutrition, and health services. Nonworking older persons have a 1.6-fold greater risk of fall-related injury in comparison with working older persons. These results agree with those of the Iraqi study, in that the risk of fall-related injury in non-working older persons is significantly greater in comparison with older persons of working status. Psychological factors, especially depression, as a result of having no occupation, which is caused by age and health conditions, are important risk factors for the occurrence of falls. ${ }^{(23)}$

One limitation of this study is the lack of data on impairment of balance so that it cannot explain the role of balance in the risk of falls in older persons. In addition, the lack of information on the conditions of the site of injury, e.g. multistory buildings, slippery floors, roads with potholes or uneven surfaces and others, so that these cannot be used as further information on the role of environmental factors on the risk of falls. There is a need for further studies to determine the role of environmental conditions on fall-related injury.

To reduce the resulting morbidity and mortality, internal preventive measures need to be taken, i.e. behavioral changes for a healthy life style, such as consumption of healthy foods to avoid diseases such as stroke, limiting salty foods to avoid hypertension, managing emotions to avoid stress, sufficient rest and routine physical exercise. $^{(23)}$ It is important for older persons to control their health status by routine blood pressure measurements, periodic ophthalmologic examinations, positive socializing such as participating in health gymnastics or religious studies (pengajian) to prevent boredom, and using walking aids if necessary. Based on the results of this study, the Ministry of Health and the Regional Government should cooperate in increasing community health services by maximizing the functioning of community health centers (puskesmas) in monitoring and guiding the community, particularly those families at high risk of poor health (both healthy older persons and those with chronic diseases).

\section{CONCLUSION}

Older women and those with a history of stroke are at greater risk for fall-related injury.

\section{CONFLICT OF INTEREST}

There was no conflict of interest in this study.

\section{ACKNOWLEDGMENT}

The authors express their deep-felt gratitude to: Prof. dr. Bastaman Basuki and dr. Iwan Ariawan of FKM-UI who provided guidance and directions in the analysis of the Riskesdas data, so that the results may be of benefit to all parties, particularly to decision and policy makers. Our colleages of the advanced analysis team for their cooperation so that this study could proceed smoothly and succesfully.

\section{REFERENCES}

1. Jamebozorgi AA, Kavoosi A, Shafiee Z, et al. Investigation of the prevalent fall-related risk factors of fractures in elderly referred to Tehran Hospitals. Med J Islamic Republic Iran 2013;27:23-30.

2. Riyadina W. Profil cedera akibat jatuh, kecelakaan lalu lintas dan terluka benda tajam/ tumpul pada masyarakat Indonesia. Jurnal Penyakit Tidak Menular. 2009;1:1-11. 
3. Kementerian Kesehatan. Pokok-pokok hasil Riskesdas 2013. Jakarata: Badan Penelitian dan Pengembangan Kesehatan Kementerian Kesehatan;2014.

4. Lok N, Akin B. Domestic environmental risk factors associated with falling in elderly. Iranian J Publ Health 2013;42:120-8.

5. Damian J, Pastor-Barriuso R, Valderrama-Gama $\mathrm{E}$, et al. Factors associated with falls among older adults living in institutions. BMC Geriatrics 2013;13:6.

6. Sabatini SN, Kusuma HE, Tambunan L. Faktor eksternal risiko jatuh lansia: studi empiris. Prosiding Temu Ilmiah IPLBI; 2015 Okt 30-31; Manado, Sulawesi Utara; 2015.p.1-6.

7. Reed-Jones RJ, Solis GR, Lawson KA, et al. Vision and falls: multidisciplinary review of the contribution of visual impairment to falls among older adults. Maturitas 2013;75:22-8.

8. Rodriguez IG, Fraga GP, De Azevedo Barros MB. Falls among the elderly: risk factors in a population-based study. Rev Bras Epidemiol 2014;705-18. DOI: 10.1590/1809-45032014000 30011.

9. Jalayondeja C, Sullivan PE, Pichaiyongwongdee S. Six-month prospective study of fall risk factors identification in patients post-stroke. Geriatr Gerontol Int 2014;14:778-85.

10. Riyadina W. Cedera akibat jatuh pada penduduk usia lanjut yang mengalami obesitas di Indonesia. Jurnal Penyakit Tidak Menular 2009; 1:73-83.

11. Williams SJ, Kowal P, Hestekin H, et al. Prevalence, risk factors and disability associated with fall-related injury in older adults in lowand middle-income countries: results from the WHO Study on Global AGEing and adult health (SAGE). BMC Medicine 2015;13:1-12. doi: 10.1186/s12916-015-0390-8.

12. Kameel MH, Abdulmajeed AA, Ismail SE. Risk factors of falls among elderly living in Urban Suez - Egypt. Pan African Med J 2013;14:26. doi:10.11604/pamj.2013.14.26.1609.

13. Kementerian Kesehatan RI. Pedoman Pemeriksaan Riset Kesehatan Dasar. Jakarta: Badan Penelitian dan Pengembangan Kesehatan; 2013.
14. American Academy of Family Physicians. Joint National Committee (JNC) - 8 Guidelines for the management of hypertension in adults. Am Fam Physicians-2014;90:503-4.

15. Gray LJ, Yates T, Davies MJ, et al. Defining obesity cut-off points for migrant South Asians. PLoS ONE 2011;6: e26464. doi:10.1371/ journal.pone.0026464.

16. Grundstrom AC, Guse CE, Layde PM. Risk factors for falls and falls-related injuries in adults 85 years of age and older. Arch Gerontol Geriatr 2012;54: 421-8.

17. Pi HY, Hu MM, Zhang J, et al. Circumstances of falls and fall-related injuries among frail elderly under home care in China. Int J Nursing Sciences 2015;2:237-42. Available at: http:// dx.doi.org/10.1016/j.ijnss.2015.07.002.

18. Orces $\mathrm{CH}$. Prevalence and determinants of falls among older adults in Ecuador: an analysis of the SABE I Survey. Current Gerontol Geriatr Res 2013;1-7. Article ID 495468, 7 pages. http:/ /dx.doi.org/10.1155/2013/495468.

19. Kuang TM, Tsai SY, Hsu WM, et al. Visual impairment and falls in the elderly: the Shihpai Eye Study. J Chin Med Assoc 2008;71:467-72.

20. Prihatini S, Vita KM, Abas BJ, et al. Faktor determinan risiko osteoporosis di tiga provinsi di Indonesia. Media Litbang Kesehatan 2010;20: 91-9.

21. Thurman DJ, Stevens JA, Rao JK. Practice parameter: assessing patients in a neurology practice for risk of falls (an evidence-based review): report of the quality standard subcommittee of the American Academy of Neurology. Neurology 2008;70:473-9.

22. Hayashi T, Kondo K, Suzuki K, et al. Factors associated with falls in community-dwelling older people with focus on participation in sport organization: the Japan Gerontological Evaluation Study Project. Bio Med Research Int 2014;1-10.

23. Qader MAA, Amin RM, Shah SA, et al. Psychological risk factors associated with falls among elderly people in Bagdad City. Iraq Open J Prev Med 2013;3:441-5. 